\title{
Skin Response Original Result Unit
}

National Cancer Institute

\section{Source}

National Cancer Institute. Skin Response Original Result Unit. NCI Thesaurus. Code C117680.

The unit of measure for the result of the skin response test or finding as originally received or collected. 